\title{
What do We Talk about When We Talk about Social-Ecological Systems? A Literature Review
}

\author{
Cristina Herrero-Jáuregui ${ }^{1, *}$, Cecilia Arnaiz-Schmitz ${ }^{2}$, María Fernanda Reyes ${ }^{3}$, \\ Marta Telesnicki ${ }^{3}$, Ignacio Agramonte ${ }^{4}$, Marcos H. Easdale ${ }^{5}$, María Fe Schmitz ${ }^{1}$, \\ Martín Aguiar ${ }^{3}$, Antonio Gómez-Sal ${ }^{6}$ and Carlos Montes ${ }^{2}$ \\ 1 Departament of Biodiversity, Ecology and Evolution, Complutense University of Madrid, \\ 28040 Madrid, Spain; ma296@bio.ucm.es \\ 2 Socio-Ecosystems Laboratory, Autonomous University of Madrid, 28049 Madrid, Spain; \\ cecilia.arnaiz@uam.es (C.A.-S.); carlos.montes@uam.es (C.M.) \\ 3 IFEVA, Faculty of Agronomy, University of Buenos Aires, C1417DSE Buenos Aires, Argentina; \\ freyes@agro.uba.ar (M.F.R.); mtelesnicki@agro.uba.ar (M.T.); aguiar@agro.uba.ar (M.A.) \\ 4 Department of Botany, Institute of Ecology and Earth Sciences, University of Tartu, 51003 Tartu, Estonia; \\ ihernandez@agro.uba.ar \\ 5 National Institute for Agricultural Technology (INTA), Bariloche \& CONICET, 8400 San Carlos de Bariloche, \\ Argentina; easdale.marcos@inta.gob.ar \\ 6 Life Sciences Department, Ecology, University of Alcalá, 28801 Alcalá de Henares, Spain; \\ antonio.gomez@uah.es \\ * Correspondence: crherrero@bio.ucm.es; Tel.: +34-91-3945056
}

Received: 17 July 2018; Accepted: 16 August 2018; Published: 20 August 2018

\begin{abstract}
In the last decade, probably in response to global changes and the environmental crisis, the use of the term "social-ecological system" (SES) in scientific literature has grown. This is certainly a sign that the need and importance of transdisciplinary research has been recognized. Here, we explore whether the use of the term is a buzzword or, rather, actually represents a key concept in the integration of social and ecological research. We compiled a database of publications $(N=1289)$ that mentioned SES in the title, keywords and abstract. Subsequently, we analyzed the authors' affiliations, type of work (conceptual, empirical or review), study site, prevailing human use, temporal and spatial scales of the analysis, kind of variables analyzed (socioeconomic or biophysical), and the method/s used to integrate them. We detected four time spans in the use of the term (1975-1997, 1998-2006, 2007-2012, 2013-2016). Our results suggest that SES is a widely invoked concept in the study of the interface between social and ecological systems. Most works show some common elements, such as the analysis of resilience, ecosystem services, sustainability, governance and adaptive management. However, the majority of studies do not study SES as a whole, integrating both social and ecological variables and their feedback loops. We consider SES as a concept still in construction in order to build a necessary framework for the integration of social and ecological sciences. For a robust evolution, we recommend that one focus on: (i) A conscious, discussed and agreed effort of scientists to conduct the transdisciplinary research needed to study SES; and (ii) the development of methodological tools for the true integration of social and ecological data.
\end{abstract}

Keywords: adaptation; complex adaptative systems; ecosystem services; governance; resilience; sustainability; transdisciplinary

\section{Introduction}

The widespread and profound, wanted or unwanted, changes observed around the Earth have prompted the recognition that there is an urgent need to understand the ways in which humans affect 
and are affected by nature. It has become essential to work in the complex interface of ecological and social systems, which is where policies concerning land use are developed [1,2]. However, the fact that the proportion of pristine ecosystems is minor, and most of our ecological understanding derives from conservation areas, e.g., national parks, hinders true appreciation of the complexity of our living ground [3]. For example, managed or transformed ecosystems have lost large-size species, top predators, and many exotic species, which are common components of communities. There is indeed an increasing consensus that many of the complex world issues relating to the environmental crisis require management under the framework of sustainable development, as has been expressed in the Sustainable Development Goals (SDGs) [4]. Many aspects of the environmental crisis, considered at the launch of the Millennium Development Goals (2000), have been carried forward to SDGs because they are complex issues to be dealt within the social-ecological system (SES) framework. In turn, this involves integrating the social and natural sciences, and there is a growing agreement that transdisciplinary research is a key tool in facing environmental challenges. Hence, there is a need to expand the boundaries of the studied systems. These modifications mean shifting the object of study towards social-ecological systems [5-7].

The terms "socio-ecological system", "socio-ecosystem" and "social-ecological system" (henceforth, SES) are used synonymously and have emerged to address this complexity and integrate the social and ecological sciences. It is an anthropocentric concept, which appeared in the Anthropocene context of global change. The theoretical formalization of the concept has triggered research and literature into SES [4,8-14] (among others). Nowadays, these terms are widely used in environmental sciences. However, as with many other complex concepts associated with terms that have become fashionable buzzwords in the history of environmental sciences (e.g., biodiversity, resilience, governance, sustainability), there is a risk of these important concepts falling into confusion or banalization [15-17], emptying them of clear significance. The concept is not rigid [13] and there are different approaches and perspectives relating to the understanding of it $[18,19]$, although it can also be used as a commonplace term because it is trending. In fact, several authors do not believe that there is a need for this new concept to be coined, as ecosystems already include social systems, since humans are part of nature [20].

Social-ecological systems, as complex adaptive systems, possess emergent properties [21,22], and resilience, or the system's ability to continue to function when intrinsic or extrinsic disturbances occur, is one of the most important [4,22]. SESs constitute co-evolving systems in which territorial and socioeconomic structures maintain constant and reciprocal interactions $[4,6]$. The biophysical-cultural coevolution in which agriculture has risen is a clear example of this. The emergent properties that are susceptible to identification and analysis depend on the social and ecological nature of the variables considered, their scale and the study methods used. However, cultural and ecological processes operate at different spatial and temporal scales, and it is thus difficult to find appropriate methodologies to measure and combine both types of variables at a meaningful and appropriate scale $[23,24]$.

The aim of this systematic literature review is to analyze what has been considered and published under the term of SES since it first appeared. Specifically, the type of work where SESs are considered, where and by whom, under which kind of management, the type of variables analyzed, the temporal and spatial scales, and the methodology used. Drawing on the results, we address the main landmarks in the history of SES and discuss some major points derived from the analysis of the data, especially related to the asymmetries that might be identified. These potential unbalances refer to issues, such as theory vs. empirical evidence, biophysical vs. socioeconomic and cultural variables, agricultural intensification vs. urban expansion, and SES in developing countries vs. SES in developed countries. Based on the results, we elaborate some recommendations for the use of the term and the promotion of the concept. We believe the results of this review will be useful for defining the state of the art, identifying gaps in knowledge and addressing future research lines. 


\section{Methods}

In December 2017, we conducted a review in Scopus, searching for the terms "socio-ecosystem", "social-ecological system", "socio-ecological system" and their Spanish translations, excluding those related to the areas of biomedicine, business, mathematics and physics, in the title, keywords and abstract. We used Scopus as the main database but also explored the trajectories of researchers and research groups using Google Scholar.

To detect the evolution of the use of the considered terms, referring to SES, we classified the number of published papers based on either biophysical or socioeconomic variables, independently, or on the combination of both types of variables. On the basis of this temporal classification, we performed multiple aggregation analyses of consecutive years, which were later validated by simple regression analyses, in order to detect discontinuities in the trend of the use of the term. The sets of selected years were those whose coefficient of determination (proportion of the variance 'explained' by the regression model) exceeded 70\%. The statistical difference between the consecutive groups of years was performed using a mean comparison analysis (Fisher F-test; $k>2$ ) that allowed us to characterize a qualitative variable (sets of years) by a quantitative variable (number of papers). From the stratified temporary database, we randomly selected a sample of $70 \%$ of the studies of each group of the years detected. Therefore, the final analyzed sample consisted of 990 papers. We deleted studies from 2017 because of the time-lagged response in the publication process.

In each study, we looked for information related to the characteristics of the publication, the importance given to the term, the management system studied, the scale of the analysis, the variables analyzed and the analytical procedures (Table 1). We assessed the importance given to the term by considering whether the authors defined the term and/or cited previous definitions. We built a data matrix that was analyzed by means of descriptive statistics, mainly including measures of frequency, using R 3.4.2 [25].

We characterized each country by its Gross National Income per capita (GNI, reported in U.S.\$; https:/ / data.worldbank.org/indicator) and used Social network analysis (SNA) to analyze the relationships between the funding country of the research (nodes; units of the network) and the country where the study area was located (edges, links or interactions between nodes, symbolized by arrows). The intensity of this relationship is represented by the thickness of the links, which mean the number of papers that share the same link (the two countries in relation, the financer and financed). The direction of the links indicates the direction of the financing (financing country at the beginning of the arrow, country financed at the end of the arrow). The size of each node corresponds to the total number of papers published by each country. When a country is both funder and funded, there is no a graphical representation of the link, and this situation is expressed by increasing the size of the corresponding node. These concepts are displayed in a social network diagram, where nodes are the points, and edges are the lines. We used the package network D3 from R [26].

Table 1. List of variables considered in each study and the corresponding attributes.

\begin{tabular}{llc}
\hline \multicolumn{1}{c}{ Variables } & Attributes & Objectives \\
\hline Publication characteristics & & Description \\
\hline Type of publication & Empirical, Theoretical, Modeling, Review & \\
\hline Year of publication & & Origin in natural or social sciences \\
\hline Organization of the first author & & Assessing the importance given to the \\
\hline Country's Gross National Income (2018) & & "social-ecological system" (SES) term \\
\hline Subject area of publication & Environmental, biological or social sciences \\
\hline Importance given to the term & & \\
\hline Location of the term & Title, abstract, keywords & \\
\hline Definition of the term & Yes, no & \\
\hline
\end{tabular}


Table 1. Cont

\begin{tabular}{|c|c|c|}
\hline Variables & Attributes & Objectives \\
\hline \multicolumn{3}{|l|}{ Characteristics of the system studied } \\
\hline Location of the study area & Countries, places of study inside countries & \\
\hline Main management/ focus of publication & $\begin{array}{l}\text { Fishery, agriculture, conservation, cattle ranching, } \\
\text { urbanization, forestry, tourism, agro-silvo-pastoral, hunting, } \\
\text { restoration, mining }\end{array}$ & $\begin{array}{l}\text { Description of the management system } \\
\text { studied }\end{array}$ \\
\hline Scale of analysis & & $\begin{array}{l}\text { Temporal and spatial scales at which the } \\
\text { studies are conducted }\end{array}$ \\
\hline Temporal scale & Days, months, years, centuries & \\
\hline Spatial scale & Local, regional, global & \\
\hline Variables analyzed & & Type of variables mostly analysed \\
\hline Analytical procedures & & $\begin{array}{l}\text { Methods used to combine different types of } \\
\text { variables }\end{array}$ \\
\hline $\begin{array}{l}\text { Analysis of both biophysical and } \\
\text { socioeconomic variables }\end{array}$ & Yes, no & \\
\hline Methods used to combine both variables & $\begin{array}{l}\text { Models, multivariate analysis, geographical information } \\
\text { techniques }\end{array}$ & \\
\hline
\end{tabular}

\section{Results}

Based on the change in the slope of the linear fitting equations and the results of the mean comparison test, it was possible to differentiate four different time spans in the use of the term: 1975-1997, 1998-2006, 2007-2012, 2013-2016, with an increasing rate of published papers per year (Figure 1). The number of papers published in each period was significantly different from the number of papers published in the other periods identified ( $F$-test, $p<0.05)$.

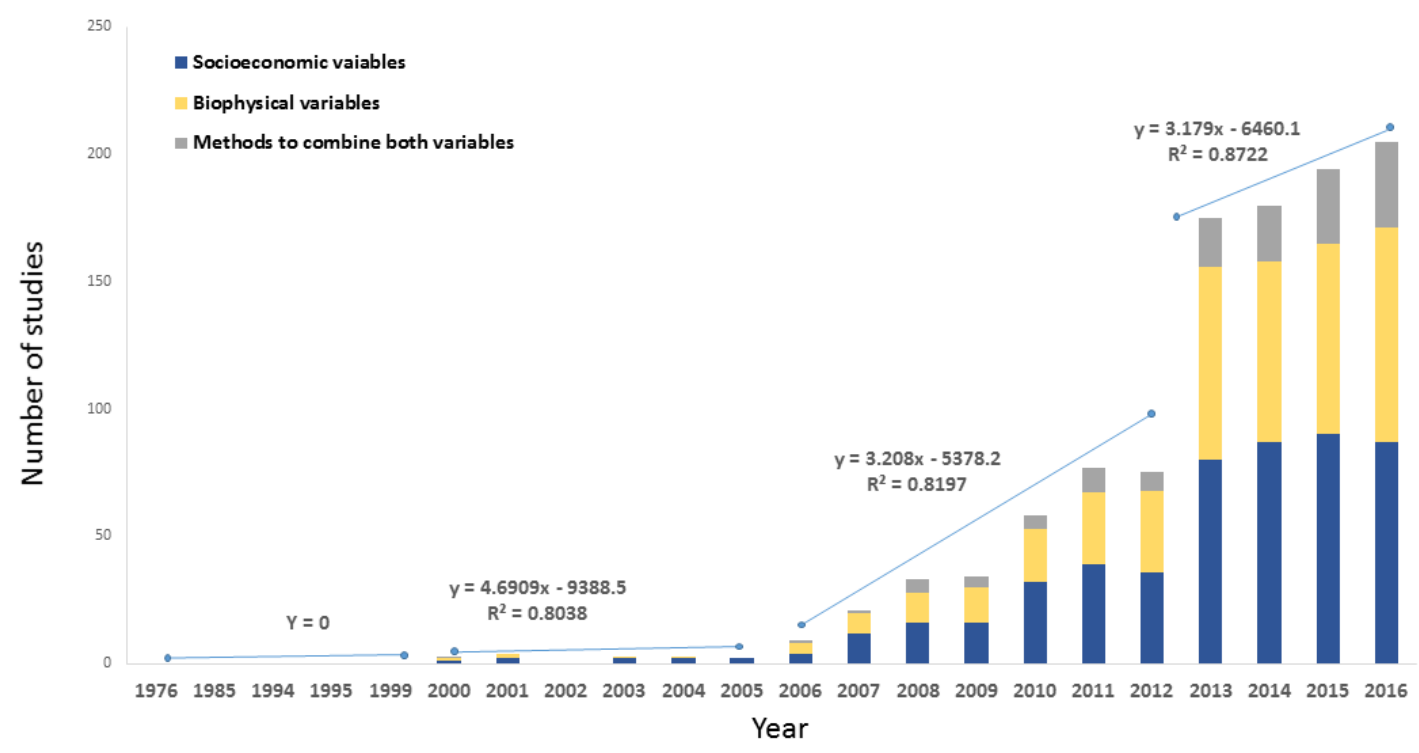

Figure 1. Evolution of analyzed publications containing the term "social-ecological system" (SES) in the title, abstract or keywords. Dashed lines adjust the different periods detected. The regression equation and the coefficient of determination $\left(R^{2}\right)$ are shown. Blue and yellow colors indicate the number of publications that use either biophysical (blue) or socioeconomic (yellow) variables. In gray, the number of publications that use a mathematical method to integrate both types of variables. 
Throughout these periods, a total of 1059 organizations were represented, although only a few of them could be considered as SES-specialists, having led, as the primary institution, at least five papers on this topic. For example, the Stockholm Resilience Center led, as the primary institution, 32 papers, followed by the Natural Resource Institute of Manitoba and the Arizona State University with 13 and 10 papers, respectively (Figure 2a).

The great majority of SES studies corresponded to research articles in the domain of environmental sciences $(60 \%)$, followed by social sciences $(25 \%)$ and agricultural and biological sciences $(15 \%)$ (Figure $2 b$ ). Of these studies, $62 \%$ were conducted by researchers whose origin was in the natural sciences, while $30 \%$ had their origin in the social sciences.

The ten most frequently used keywords, associated with SES, were resilience, ecosystem services, sustainability, governance, adaptation, vulnerability, adaptive management, climate change, adaptive capacity and institutions (Figure 2c). Only $4 \%$ of publications mentioned SES in the keywords without studying it explicitly. With regard to defining the term, $16 \%$ of analyzed papers included a general definition of SES, whereas $29 \%$ cited someone as a reference for it. The most cited definition was the one proposed by Berkes and Folke [8].

Empirical studies were the most numerous ( $42 \%$ ). These studies generated and analyzed the data of concrete study systems and were followed by conceptual papers (34\%) and reviews or meta-analysis (21\%) of different topics related to SES. Of the conceptual papers, $20 \%$ described some kind of model for the analysis of SES behavior in space and/or time (Figure 2d). The main spatial scale of analysis at which SESs were studied was local (53\%), followed by regional (38\%) and global (9\%). Most temporal scales were in the range of 1-3 years, although there were several studies in the range of 30-100 years.

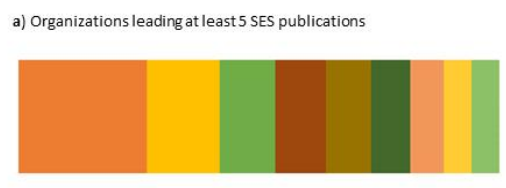

Stockholm Resilience Centre, SW = Arizona State University, USA

m Department of Systems Ecology (Stockholm University), SW

- Department of Natural Resources, USA - Wildlife Conservation Society, USA

b) Subject area of publication

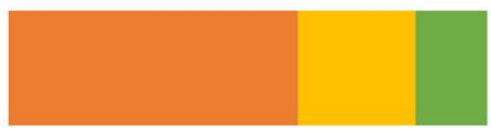

Environmental Science

Social Science

Agricultural and Biological Sciences c) The first 10 mostly used keywords

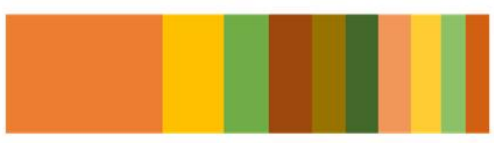

- Resilience

Sustainability

- Adaptation

Adaptative capacity

d) Type of study

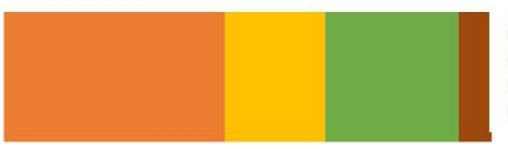

Empirical

Review,meta-analysis

- Conceptual

Models

Figure 2. Percentage of studies belonging to different publication characteristic categories.

In empirical studies, the "type of management" most often analyzed related to productive activities, mainly fishing and agriculture (Figure 3a). The variables most frequently recorded in empirical studies were of the socioeconomic type (91\%), almost doubling in importance studies that reported on biophysical variables (52\%). In each type, variables from interviews at the local scale $(32 \%$, Figure $3 b)$, as well as mapping and remote sensing analysis at the regional scale (36\%, Figure $3 c)$, were the most frequently reported. Only $43 \%$ of empirical studies gathered field data of both biophysical and socioeconomic variables, and half of these used some quantitative method to integrate both types of variables. The most frequent combining methods were mainly related to geographical information techniques, quantitative models, and multivariate analyses. The average inter-annual 
increase in the use of socioeconomic variables was 1.26 times higher than the increase in the use of biophysical ones and 2.58 times higher than the increase in methods integrating both types of variables (Figure 4).

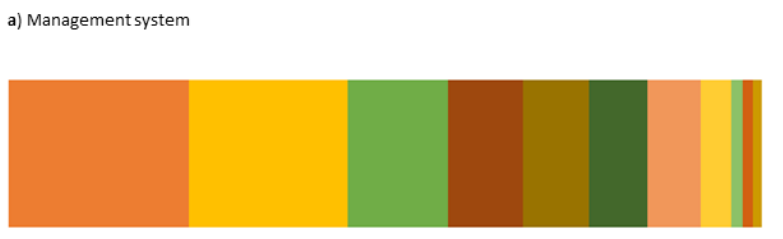

घ Fishery

a Conservation a Urbanization घTourism

a Hunting

a Minery $\square$ Agriculture

a Cattle ranching

- Forestry

Agro-silvo-pastoral

a Restoration

b) Socioeconomic variables

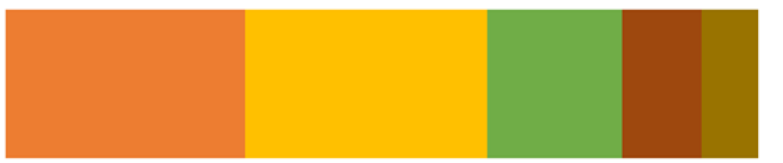

a Interviews

a Previous surveys

a Socioeconomic indicators

- Workshops

Q Participant obsenvation

c) Biophysical variables

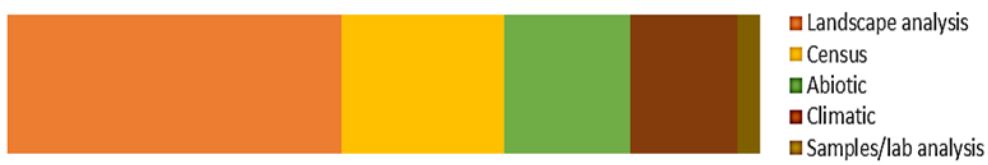

Figure 3. Characteristics of empirical studies addressing social-ecological systems (SES).

Methods to integrate both variables

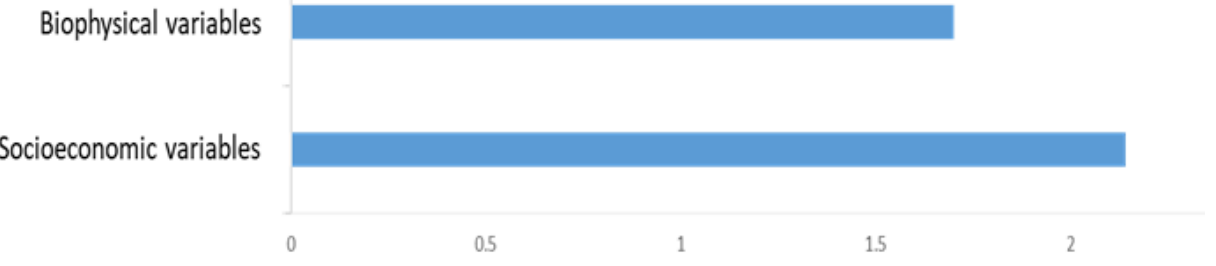

Percentage

Figure 4. Average interannual variation of studies analyzing socioeconomic or biophysical variables or integrating both types of variables, in relation to the total number of papers reviewed each year between 1976 and 2016.

The majority (53\%) of the empirical studies (i.e., developed in a determined study area) were financed and elaborated by countries of the so-called Global North (a term that denotes the generic geographic, historical, economic, educational, and political division between north and south). Moreover, $60 \%$ of these studies led by organizations of the Global North were conducted in countries of the Global South (as is expressed by the arrow direction between the nodes, shown in Figure 5). 
GNI $<25.000 \$$

GNI $>25.000 \$$

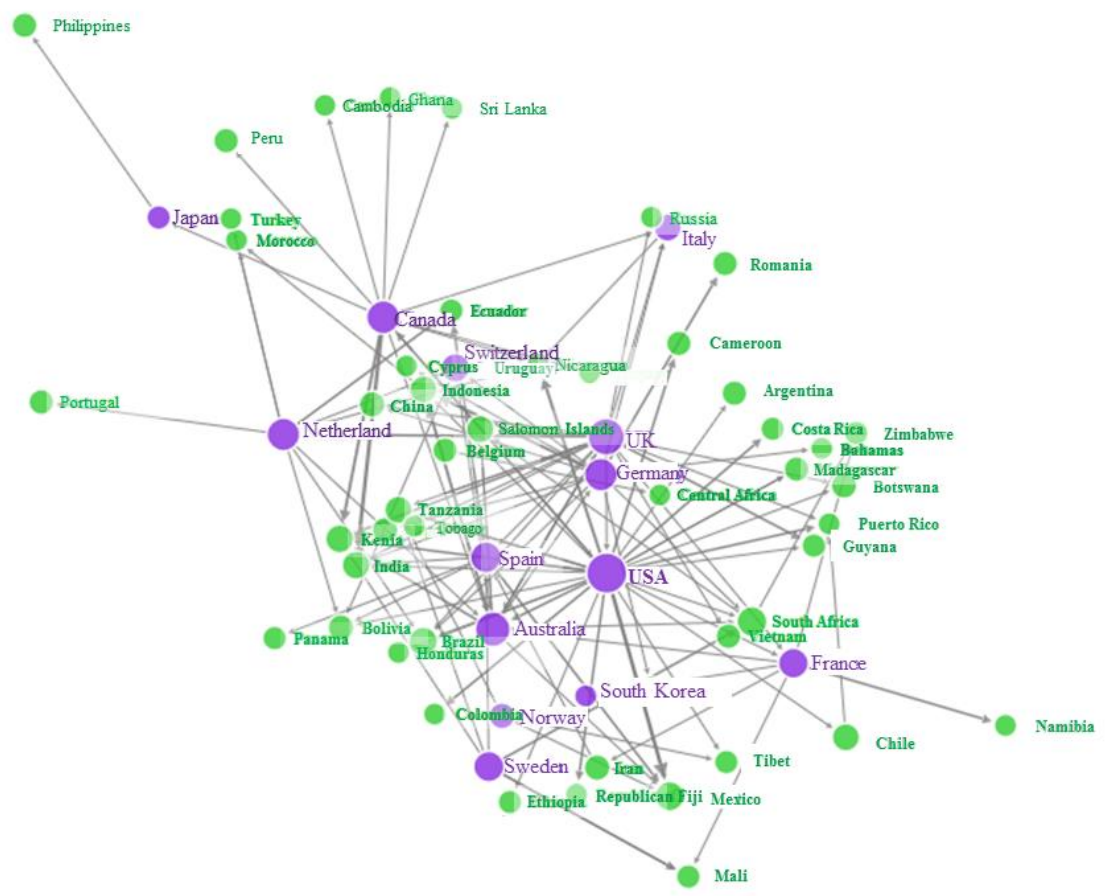

Figure 5. Social Network Analysis, showing the relationship between the funding country of the research (nodes) and the country where the study area is located (edges). The number of papers that share the same relationship is represented by the thickness of the links. Countries of the Global South (gross national income $(\mathrm{GNI})<25,000$ U.S.\$ per capita) are represented in green, and countries of the Global North (GNI > 25,000 U.S.\$ per capita), in purple.

\section{Discussion}

\subsection{Evolution of the Term}

The temporal dynamics of the publication rate, at four different consecutive and overlapping phases (Figure 1), can be explained by some key works and actions. The term "social-ecological system" was first published by Crook et al. and Emory and Harris [27,28] in the context of animal behavior, and was followed by Goldberg, who studied some of the coping strategies of "human-centered socioecological systems" [29]. In this period, there was not a common understanding of what SES meant, but researchers used the term to refer to social-ecological relationships when they understood that what they intended to study was not included under the concept of ecosystem. Berkes and Folke started to use the concept of SES as an integrated approach of "humans-in-nature", linking it to the concept of resilience and emphasizing the biophysical limits of nature [8]. Concurrently, Simon Levin used Holland's concept of complex adaptive systems to describe SESs as non-hierarchical and dynamic systems [9]. The concept was further developed when Berkes and collaborators schematized its multi-scalar and nested properties [10]. This formalization of the term, and the foundation of the Resilience Alliance (RA) in 1999, probably triggered the "second phase" of SES history, from 1999-2006, during which the number of publications using SES, linking it to the concept of complex adaptive systems, started to grow (mean rate $=4.06$ ).

In 2007, the Stockholm Resilience Centre (SRC) was funded, jointly embracing the concepts of resilience and SES [30]. Since then, the number of publications has grown at a faster rate (mean rate $=18.23$ ) and used the term more consistently. In this phase, SESs were usually related to socio-ecological resilience, understood as "the capacity to adapt or transform in the face of change in social-ecological systems, particularly unexpected change, in ways that continue to support human well-being" [30]. Associated with the recently created SRC, Ostrom and collaborators proposed 
a general framework for the analysis of SES and defined the variables that were to be measured in each SES subsystem in order to study it [12]. Concurrently, Glaser and collaborators proposed a working definition for the concept of SES that included governance systems: "a social-ecological system consists of a bio-geo-physical unit and its associated social actors and institutions" [31]. In 2013, the SRC incorporated the term SES in the program of SDG, and this probably prompted the "fourth phase" (mean rate $=20.60$ ) in the use of SES, from 2012 onwards, during which the number of publications significantly increased. In this fourth phase, the term was linked to governance systems, and it is noteworthy that the socioeconomic variables recorded were relatively more abundant than the biophysical ones (Figures 1 and 4). This is probably related to the fact that the majority of these publications focused on land management and decision-making.

\subsection{The Matter of Socio-Ecological Systems: What, Who, How, and Where?}

Half of all publications referred to empirical studies that generated and analyzed either primary data obtained in the field or secondary data. The rest of the publications were conceptual studies that did or did not propose a model and were based on reviews and descriptions. Empirical studies mostly incorporated socioeconomic variables through semi-structured interviews, particularly in the fourth phase (from 2012 onwards, Figure 4). This is probably related to the fact that the incorporation of SES to SDGs implied decision-making and management issues that were mostly accomplished using socioeconomic information. However, it is remarkable that these efforts, mostly published in journals of environmental sciences, were typically made by researchers from institutions linked since their origin to the natural sciences. This suggests a greater research motivation of natural scientists to study SES, which is not mirrored by institutions rooted in the social sciences. However, there is an implicit risk of researchers with insufficient background in the social sciences simplifying the social complexity of SES by incorporating just a few socioeconomic variables. Anyhow, this reflects an answer to the urgent need for change in the working system, from natural ecosystems to the interface of ecological and social systems [3,32] accompanying the emergence of the new science of sustainability [4].

However, ironically, parallel to this turn of natural scientists to working with socioeconomic data, there were comparatively few studies that analyzed biophysical variables, and the ones that did mostly based them on landscape and remote sensing analysis at regional scales. The study of SES is typically related to the study of ecosystem services; however, evidence suggests that the biophysical functions of ecosystem services are progressively being neglected. This result supports the need of incorporating biophysical information in the study of SES [33,34] and reflects the challenge of acquiring datasets measured at a fine resolution. Indeed, the spatial scale at which studies were conducted was mostly local, which was probably oriented toward the analysis of any specific kind of management, and, secondly, regional, which was mainly oriented toward governance studies. This evidence suggests that there is a gap between theoretical developments and empirical information that is able to effectively integrate social and biophysical data.

The different spatial and temporal scales at which sociological and ecological processes operate make it difficult to find appropriate methodologies to combine both types of variables at a meaningful scale and study SES in a way that aims to extract the emerging properties of the variables [24,35-37]. To avoid scale-driven mismatches between these different sources of data, and to generate sound inferences, data must be assembled into a single and comparable scale [38,39] (pp. 23-40), which is not a trivial challenge. In fact, although around $40 \%$ of empirical studies reported both biophysical and sociological variables, only the half tried to develop tools to integrate both sets of variables. These efforts were mainly accomplished using geographic information systems, multivariate analysis, and mathematical models, such as multiple regression analysis [6,40-42] or Bayesian networks [43-45]. Thus, there is room for developing SES studies by using analyses that combine both sets of variables at different spatial and temporal scales. Social-ecological network approaches are promising tools for social-ecological analysis [46]. Some applications include the role of social networks in natural resource management [47], the spatial organization of biological populations in fragmented landscapes [48], 
scale mismatches, and the value of social networks [49] and networks that consider ecological sites, which are interconnected by a mobile livelihood strategy, such as transhumant pastoralism [5]. Canonical correspondence analyses are also promising tools for jointly analyzing social and ecological structures, such as land cover, landscape configuration, and the socioeconomic characteristics of populations $[7,50]$. In a complementary fashion, it is important to develop a conceptual discussion among disciplines involved in the study of SES. Social research must engage in biophysical analysis as well as the reverse, embracing all the profundity and theoretical background of both the social and natural sciences.

Regarding the studied management system, most of studies referred, as expected, to productive activities, mainly fishing and agriculture. While agriculture is the human activity that occupies most of the land surface of the Earth, together with rangelands [3], fishing is the only productive activity, based on a wild resource, that implies such a volume of market and population. Additionally, fisheries tend to suffer from the tragedy of the commons at the national level [51]. Over-fishing alerts may be a geopolitical strategy for controlling fisheries in non-territorial waters, as risking such a resource would produce an enormous impact on societies and the economy on a global level. Therefore, it could have been this imminent risk and the catastrophic consequences for societies that triggered the joint study of societies and ecosystems under the term of social-ecological systems. In fact, it is in the coastal areas, where the experiences and theory of 'integrated management' encourage consideration of the variables of different disciplines, have had more development. Something similar has happened in "integrated watershed management" [52]. In contrast, despite the recognized importance of urban ecology and "novel ecosystems" [53,54], comparatively few studies on analyzed SES management activities typically related to urban or suburban areas, such as urbanization, tourism or waste production (but see [55-60]). Analysis of rural-urban gradients from an SES perspective is also an understudied but promising field [50]. Additionally, whereas warfare affects a large portion of ecosystems, often with profound changes [61], very few studies implicitly considered this factor in their analysis (but see [62]).

Finally, studies on SES are equally represented in countries with high and low GNI, contrary to what Martin et al. found when mapping where ecologist worked (Figure 5) [3]. This can reveal a hidden link between SES and rurality, traditional practices, conflictive socioeconomic scenarios and other issues related to developing countries. However, the fact that most of the studies conducted in the Global South came from organizations affiliated with the Global North means that they are dominated by northern research agendas, which do not necessarily address research questions of local interest that can help to solve social-ecological challenges $[63,64]$. Research practices must incorporate a clear awareness of the fact that theory and practice come from systems that are placed within some specific cultural context. This can help in moderating naive expectations concerning the policy impact of research results [65].

\subsection{A Concept in Transition}

Results from this study suggest that, on the whole, the term SES is not a buzzword, empty of significance. On the contrary, the concept is being progressively shaped using inputs from different key works on the matter, and nowadays, the majority of publications using this term explicitly study SESs, as explained in Section 4.2. Indeed, the fourth phase reflects what Folke describes as SESs for the sustainability of human well-being [30].

However, the lack of a common use of the term also reflects that the term "social-ecological system" is not yet a clearly defined concept, accepted by all scholars. Instead, it is still a concept under construction that is integrating many currents of thought, originated in different disciplines. Despite the lack of a general definition, results of this study show some common elements in most works dealing with SES. Such common elements, evidenced by shared keywords, are, among others, resilience, ecosystem services, sustainability, governance, adaptation, vulnerability, adaptive management and climate change. These standard elements can help to build a shared definition of SES. They mostly refer to systems' emergent properties and conceptualizations of key features aimed at fostering sustainability 
pathways. However, the frequency of keywords referring to social problems- such as poverty, inequality, land grabbing, resource access conflicts, corruption, and even warfare-is comparatively smaller [66]. This situation may be due to the registered lack of participation of social scientists or to the dominant research interests highlighting resilience and adaptation as core properties for the future, rather than a critical position on current complementary social problems structuring social-ecological challenges.

Finally, the articulation of well-documented frameworks, can build bridges in terms of communication and language among scientific disciplines [67]. For example, frameworks that have originated in different research arenas, such as the state and transition model, rooted in the resilience approach and natural sciences [68], and the sustainable livelihoods approach, rooted in the vulnerability approach and social sciences [69], can provide a conceptual basis for theory and operative integration [70]. Similar examples are the search for a more integrated use of sustainability and resilience concepts in an environmental management context [71,72], as well as resilience and vulnerability [73].

\subsection{Recommendations for the Future}

Socio-ecological systems-oriented research has inspired advances in sustainability science and practice [10]. Based on results from this study, we identify six issues that we think need to be addressed in order to consolidate the study of SES throughout the world and foster progress towards sustainable development. They complement those priorities highlighted by Fischer et al. and insist on some observations made previously by other authors $[33,34]$ :

1. A shared definition for "social-ecological system" would be desirable and would help to consolidate the concept in the context of the emerging science of sustainability.

2. Social scientists should collaborate with biophysical scientists as well as the reverse, to achieve a true transdisciplinary approach in the study of SES.

3. Biophysical data based on field sampling at meaningful scales must not be forgotten in the study of SES so that scientific foundations for ecosystem services can be provided.

4. Methods for the integration of social and biophysical data at a sufficiently fine resolution, which are likely to be comparable at different scales, must be developed.

5. More emphasis should be placed on the study of SES in management activities typical of urban and suburban areas, as well as the study of SES under warfare and social conflict scenarios.

Author Contributions: C.H.-J., C.A.-S., M.F.R., I.A., M.H.E., M.A. and A.G.S. conceived and designed the study; C.H.-J., C.A.-S., M.F.R., M.T., I.A. and M.H.E. conducted bibliographical research, reviewed the papers and built the data matrix; C.H.-J., C.A.-S., M.F.R. and M.T. analyzed the data; C.H.-J., C.A.-S., M.F.S., M.A., M.H.E. and C.M. wrote the paper.

Funding: This study was partly supported by the project, ECOGRADIENTS (CGL2014-53782-P), funded by the Spanish Ministry of Economy and Competitiveness (2015-074408).

Acknowledgments: The authors thank three anonymous reviewers for providing valuable suggestions, which have improved the quality of this paper.

Conflicts of Interest: The authors declare no conflict of interest.

\section{References}

1. Walker, B.; Carpenter, S.; Anderies, J.; Abel, N.; Cumming, G.; Janssen, M.; LEbel, L.; Norberg, J.; Peterson, G.D. Resilience management in social-ecological systems: A working hypothesis for a participatory approach. Conserv. Ecol. 2002, 6, 14. [CrossRef]

2. Castella, J.C.; Kam, S.P.; Quang, D.D.; Verburg, P.H.; Hoanh, C.T. Combining top-down and bottom-up modelling approaches of land use/cover change to support public policies: Application to sustainable management of natural resources in Northern Vietnam. Land Use Policy 2007, 24, 531-545. [CrossRef] 
3. Martin, L.J.; Blossey, B.; Ellis, E. Mapping where ecologists work: Biases in the global distribution of terrestrial ecological observations. Front. Ecol. Environ. 2012, 10, 195-201. [CrossRef]

4. Folke, C.; Biggs, R.; Norström, A.V.; Reyers, B.; Rockström, J. Social-ecological resilience and biosphere-based sustainability science. Ecol. Soc. 2016, 21, 41. [CrossRef]

5. Easdale, M.; Aguiar, M.R.; Paz, R. A social-ecological network analysis of Argentinean Andes transhumant pastoralism. Reg. Environ. Chang. 2016, 16, 2243-2252. [CrossRef]

6. De Aranzabal, I.; Schmitz, M.F.; Aguilera, P.; Pineda, F.D. Modelling of landscape changes derived from the dynamics of socio-ecological systems: A case of study in a semiarid Mediterranean landscape. Ecol. Indic. 2008, 8, 672-685. [CrossRef]

7. Schmitz, M.F.; Arnaiz-Schmitz, C.; Herrero-Jauregui, C.; Diaz, P.; Matos, D.G.; Pineda, F.D. People and nature in the Fuerteventura Biosphere Reserve (Canary Islands): Socio-ecological relationships under climate change. Environ. Conserv. 2018, 45, 20-29. [CrossRef]

8. Berkes, F.; Folke, C. (Eds.) Linking Social and Ecological Systems: Management Practices and Social Mechanisms for Building Resilience; Cambridge University Press: Cambridge, UK, 1998.

9. Levin, S.A. Ecosystems and the Biosphere as Complex Adaptive Systems. Ecosystems 1998, 1, $431-436$. [CrossRef]

10. Berkes, F.; Colding, J.; Folke, C. (Eds.) Navigating Social-Ecological Systems: Building Resilience for Complexity and Change; Cambridge University Press: Cambridge, UK, 2003.

11. Anderies, J.; Janssen, M.; Ostrom, E. A framework to analyze the robustness of social-ecological systems from an institutional perspective. Ecol. Soc. 2004, 9, 18. [CrossRef]

12. Ostrom, E. A general framework for analyzing sustainability of social-ecological systems. Science 2009, 325, 419-422. [CrossRef] [PubMed]

13. Fischer, J.; Gardner, T.A.; Bennett, E.M.; Balvanera, P.; Biggs, R.; Carpenter, S.; Daw, T.; Folke, C.; Hill, R.; Hughes, T.P.; et al. Advancing sustainability through mainstreaming a social-ecological systems perspective. Curr. Opin. Environ. Sustain. 2015, 14, 144-149. [CrossRef]

14. Virapongse, A.; Brooks, S.; Covelli Metcalf, E.; Zedalis, M.; Gosz, J.; Kliskey, A.; Alessa, L. A social-ecological system approach for environmental management. J. Environ. Manag. 2016, 178, 83-91. [CrossRef] [PubMed]

15. Palmer, J.; Cooper, I.; Van der Vorst, R. Mapping out fuzzy buzzwords-Who sits where on sustainability and sustainable development. Sustain. Dev. 1997, 5, 87-93. [CrossRef]

16. Alexander, D.E. Resilience and disaster risk reduction: An etymological journey. Nat. Hazards Earth Syst. Sci. 2013, 13, 2707-2716. [CrossRef]

17. Nobis, M.; Wohlgemuth, T. Trend words in ecological core journals over the last 25 years (1978-2002). Oikos 2004, 106, 411-421. [CrossRef]

18. Scholz, R.W.; Binder, C.R. Environmental Literacy in Science and Society: From Knowledge to Decisions; Cambridge University Press: Cambridge, UK, 2011.

19. Becker, E. Social-ecological systems as epistemic objects. In Human-Nature Interactions in the Anthropocene: Potentials of Social-Ecological Systems Analysis; Glaser, M., Krause, G., Ratter, B.M.W., Welp, M., Eds.; Routledge: New York, NY, USA, 2012; pp. 55-77.

20. Raymond, C.M.; Singh, G.G.; Benessaiah, K.; Bernhardt, J.R.; Levine, J.; Nelson, H.; Turner, N.J.; Norton, B.; Tam, J.; Chan, K.M.A. Ecosystem services and beyond: Using multiple metaphors to understand human-environment relationships. BioScience 2013, 63, 536-546. [CrossRef]

21. Holland, J. Hidden Order: How Adaptation Builds Complexity; Addison-Wesley Publishing Company: Boston, MA, USA, 1995.

22. Levin, S.; Xepapadeas, T.; Crépin, A.S.; Norberg, J.; De Zeeuw, A.; Folke, C.; Hughes, T.; Arrow, K.; Barrett, S.; Daily, G.; et al. Social-ecological systems as complex adaptive systems: Modeling and policy implications. Environ. Dev. Econ. 2013, 18, 111-132. [CrossRef]

23. Cooke, I.R.; Queenborough, S.A.; Mattison, H.A.; Bailey, A.P.; Sandars, D.L.; Graves, A.R.; Morris, J.; Atkinson, P.W.; Trawick, P.; Freckleton, R.P.; et al. Integrating socio-economics and ecology: A taxonomy of quantitative methods and a review of their use in agroecology. J. Appl. Ecol. 2009, 46, 269-277. [CrossRef]

24. Folke, C. Resilience: The emergence of a perspective for social-ecological systems analyses. Glob. Environ. Chang. 2006, 16, 253-267. [CrossRef]

25. R. Core Team. R: A Language and Environment for Statistical Computing; R Foundation for Statistical Computing: Vienna, Austria, 2017; Available online: https:/ / www.R-project.org/ (accessed on 01 May 2018). 
26. Allaire, J.J.; Gandrud, C.; Russell, K.; Yetman, C.J. Networkd3: D3 JavaScript Network Graphs from R. R Package Version 0.4. 2017. Available online: https:/ /CRAN.R-project.org/package=networkD3 (accessed on 05 May 2018).

27. Crook, J.H.; Ellis, J.E.; Goss-Custard, J.D. Mammalian social systems: Structure and function. Anim. Behav. 1976, 24, 261-274. [CrossRef]

28. Emory, G.R.; Harris, S.J. Attention, orientation and socioecological systems in cercopithecine primates. Taxonomic comparisons. Soc. Sci. Inf. 1981, 20, 537-559. [CrossRef]

29. Goldberg, M.A. Flexibility and adaptation: Some cues for social systems from nature. Geoforum 1985, 16, 179-190. [CrossRef]

30. Folke, C. Resilience (republished). Ecol. Soc. 2016, 21, 44. [CrossRef]

31. Glaser, M.; Krause, G.; Ratter, B.; Welp, M. Human-Nature Interaction in the Anthropocene-Potential of Social-Ecological Systems. GAIA 2008, 17, 77-80. [CrossRef]

32. Metzger, M.J.; Bunce, R.G.H.; Van Eupen, M.; Mirtl, M. An assessment of long term ecosystem research activities across European socio-ecological gradients. J. Environ. Manag. 2010, 91, 1357-1365. [CrossRef] [PubMed]

33. Epstein, G.; Vogt, J.; Mincey, S.; Cox, M.; Fischer, B. Missing ecology: Integrating ecological perspectives with the social-ecological system framework. Int. J. Commons 2013, 7, 432-453. [CrossRef]

34. Vogt, J.M.; Epstein, G.B.; Mincey, S.K.; Fischer, B.C.; McCord, P. Putting the "E" in SES: Unpacking the ecology in the Ostrom social-ecological system framework. Ecol. Soc. 2015, 20, 55. [CrossRef]

35. Giampietro, M. Economic growth, human disturbance to ecological systems, and sustainability. In Ecosystems of Disturbed Ground; Walker, L.R., Ed.; Elsevier: Amsterdam, The Netherlands, 1999; pp. 723-746.

36. Graymore, M.L.M.; Sipe, N.G.; Rickson, R.E. Regional sustainability: How useful are current tools of sustainability assessment at the regional scale? Ecol. Econ. 2008, 67, 362-372. [CrossRef]

37. Easdale, M.H.; Aguiar, M.R. Regional forage production assessment in arid and semi-arid rangelandsA step towards social-ecological analysis. J. Arid Environ. 2012, 83, 35-44. [CrossRef]

38. Cumming, G.S.; Cumming, D.H.M.; Redman, C.L. Scale mismatches in socialecological systems: Causes, consequences and solutions. Ecol. Soc. 2006, 11, 14. [CrossRef]

39. Prince, S.D. Spatial and temporal scales for detection of desertification. In Global Desertification: Do Humans Cause Deserts? Reynolds, J.F., Stafford Smith, D.M., Eds.; Dahlem University Press: Berlin, Germany, 2002; pp. 23-40.

40. Schmitz, M.F.; De Aranzabal, I.; Aguilera, P.; Rescia, A.; Pineda, F.D. Relationship between landscape typology and socioeconomic structure: Scenarios of change in Spanish cultural landscapes. Ecol. Model. 2003, 168, 343-356. [CrossRef]

41. Schmitz, M.F.; Matos, D.G.G.; De Aranzabal, I.; Ruiz-Labourdette, D.; Pineda, F.D. Effects of a protected area on land-use dynamics and socioeconomic development of local populations. Biol. Conserv. 2012, 149, 122-135. [CrossRef]

42. Schmitz, M.F.; Herrero-Jáuregui, C.; Arnaiz-Schmitz, C.; Sánchez, I.A.; Rescia, A.J.; Pineda, F.D. Evaluating the role of a protected area on hedgerow conservation: The case of a Spanish cultural landscape. Land Degrad. Dev. 2017, 28, 833-842. [CrossRef]

43. Aguilera, P.A.; Fernández, A.; Fernández, R.; Rumí, R.; Salmerón, A. Bayesian networks in environmental modelling. Environ. Model. Softw. 2011, 26, 1376-1388. [CrossRef]

44. Ropero, R.F.; Aguilera, P.A.; Rumí, R. Analysis of the socioecological structure and dynamics of the territory using a hybrid Bayesian network classifier. Ecol. Model. 2015, 311, 73-87. [CrossRef]

45. Ropero, R.F.; Rumí, R.; Aguilera, P.A. Modelling uncertainty in social-natural interactions. Environ. Model. Softw. 2016, 75, 362-372. [CrossRef]

46. Janssen, M.A.; Bodin, Ö.; Anderies, J.M.; Elmqvist, T.; Ernstson, H.; McAllister, R.R.J.; Olsson, P.; Ryan, P. Toward a network perspective of the study of resilience in social-ecological systems. Ecol. Soc. 2006, 11, 15. [CrossRef]

47. Bodin, Ö.; Crona, B.; Ernstson, H. Social networks in natural resource management: What is there to learn from a structural perspective? Ecol. Soc. 2006, 11, 2. [CrossRef]

48. Bodin, Ö.; Norberg, J. A network approach for analyzing spatially structured populations in fragmented landscape. Landsc. Ecol. 2007, 22, 31-44. [CrossRef] 
49. Guerrero, A.M.; McAllister, R.; Corcoran, J.; Wilson, K.A. Scale mismatches, conservation planning, and the value of social network analyses. Conserv. Biol. 2013, 27, 35-44. [CrossRef] [PubMed]

50. Arnaiz-Schmitz, C.; Schmitz, M.F.; Herrero-Jáuregui, C.; Gutiérrez-Angonese, J.; Pineda, F.D.; Montes, C. Identifying socio-ecological networks in rural-urban gradients: Diagnosis of a changing cultural landscape. Sci. Total Environ. 2018, 612, 625-635. [CrossRef] [PubMed]

51. Berkes, F. Fishermen and "The Tragedy of the Commons". Environ. Conserv. 1985, 12, 199-206. [CrossRef]

52. Heathcote, I.W. Integrated Watershed Management: Principles and Practice; John Willey \& Sons: Hoboken, NJ, USA, 2009.

53. Botkin, D.B.; Beveridge, C.E. Cities as environments. Urban Ecosyst. 1997, 1, 3-19. [CrossRef]

54. Hobbs, R.J.; Arico, S.; Aronson, J.; Baron, J.S.; Bridgewater, P.; Cramer, V.A.; Epstein, P.; Ewel, J.J.; Klink, C.A.; Lugo, A.E.; et al. Novel ecosystems: Theoretical and management aspects of the new ecological world order. Glob. Ecol. Biogeogr. 2006, 15, 1-7. [CrossRef]

55. Elmqvist, T.; Colding, J.; Barthel, S.; Borgström, S.; Duit, A.; Lundberg, J.; Andersson, E.; Ahrné, K.; Ernstson, H.; Folke, C.; et al. The dynamics of Social-Ecological systems in urban landscapes: Stockholm and the national urban park, Sweden. Ann. N. Y. Acad. Sci. 2004, 1023, 308-322. [CrossRef] [PubMed]

56. Moffatt, S.; Kohler, N. Conceptualizing the built environment as a social-ecological system. Build. Res. Inf. 2008, 36, 248-268. [CrossRef]

57. Anderies, J.M. Embedding built environments in social-ecological systems: Resilience-based design principles. Build. Res. Inf. 2014, 42, 130-142. [CrossRef]

58. Bergsten, A.; Galafassi, D.; Bodin, Ö. The problem of spatial fit in social-ecological systems: Detecting mismatches between ecological connectivity and land management in an urban region. Ecol. Soc. 2014, 19, 6. [CrossRef]

59. Schewenius, M.; McPhearson, T.; Elmqvist, T. Opportunities for increasing resilience and sustainability of urban social-ecological systems: Insights from the URBES and the cities and biodiversity outlook projects. AMBIO 2014, 43, 434-444. [CrossRef] [PubMed]

60. McHale, M.R.; Pickett, S.T.; Barbosa, O.; Bunn, D.N.; Cadenasso, M.L.; Childers, D.L.; Gartin, M.; Hess, G.R.; Iwaniec, D.M.; McPhearson, T.; et al. The new global urban realm: Complex, connected, diffuse, and diverse social-ecological systems. Sustainability 2015, 7, 5211-5240. [CrossRef]

61. SER. Society of Ecological Restoration. 2011. Available online: http://www.ser2011.org/restoration-inconflict-zones.html (accessed on 07 December 2017).

62. Zúñiga-Upegui, P.; Arnaiz-Schmitz, C.; López-Santiago, C.; Schmitz, M.F. Social-ecological complexity in an Andean region of Colombia. Unraveling the links between landscape structure and socio-economy of local population. AMBIO 2018, in press.

63. Young, O.R.; Berkhout, F.; Gallopin, G.C.; Janssen, M.A.; Ostrom, E.; van der Leeuw, S. The globalization of socio-ecological systems: An agenda for scientific research. Glob. Environ. Chang. 2006, 16, 304-316. [CrossRef]

64. Holmgren, M.; Schnitzer, S.A. Science on the Rise in Developing Countries. PLoS Biol. 2004, 2, e1. [CrossRef] [PubMed]

65. Domptail, S.; Easdale, M.H. Managing socio-ecological systems to achieve sustainability: A study of resilience and robustness. Environ. Policy Gov. 2013, 23, 30-45. [CrossRef]

66. Jerneck, A.; Olsson, L.; Ness, B.; Anderberg, S.; Baier, M.; Clark, E.; Hickler, T.; Hornborg, A.; Kronsell, A.; Lövbrand, E.; Persson, J. Structuring sustainability science. Sustain. Sci. 2011, 6, 69-82. [CrossRef]

67. Fox, W.E.; McCollum, D.W.; Mitchell, J.E.; Swanson, L.E.; Kreuter, U.P.; Tanaka, J.A.; Kreuter, U.P.; Swanson, L.E.; Evans, G.R.; Heintz, H.T.; et al. An integrated social, economic, and ecologic conceptual (ISEEC) framework for considering rangeland sustainability. Soc. Nat. Resour. 2009, 22, 593-606. [CrossRef]

68. Bestelmeyer, B.T.; Briske, D.D. Grand challenges for resilience-based management of rangelands. Rangel. Ecol. Manag. 2012, 65, 654-663. [CrossRef]

69. Scoones, I. Sustainable Rural Livelihoods: A Framework for Analysis; IDS: Brighton, UK, 1998.

70. Easdale, M.H.; López, D.R. Sustainable livelihoods approach through the lens of the state-and-transition model in semi-arid pastoral systems. Rangel. J. 2016, 38, 541-551. [CrossRef]

71. Carpenter, S.; Walker, B.; Anderies, J.M.; Abel, N. From metaphor to measurement: Resilience of what to what? Ecosystems 2001, 4, 765-781. [CrossRef] 
72. Marchese, D.; Reynolds, E.; Bates, M.E.; Morgan, H.; Clark, S.S.; Linkov, I. Resilience and sustainability: Similarities and differences in environmental management applications. Sci. Total Environ. 2018, 613-614, 1275-1283. [CrossRef] [PubMed]

73. Turner, B.L., II. Vulnerability and resilience: Coalescing or paralleling approaches for sustainability science? Glob. Environ. Chang. 2010, 20, 570-576. [CrossRef] 